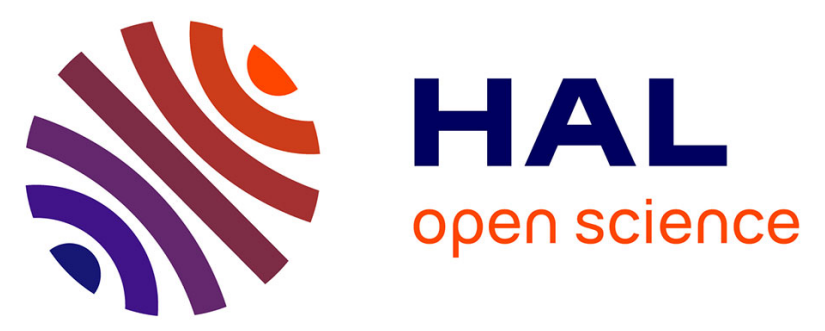

\title{
Electrical modulation of neuronal networks in brain-injured patients with disorders of consciousness: A systematic review
}

Jean-Jacques Lemaire, Anna Sontheimer, Hachemi Nezzar, Bénédicte Pontier, Jacques Luauté, Basile Roche, Thierry Gillart, Jean Gabrillargues, Sarah, D

Rosenberg, Catherine Sarret, et al.

\section{To cite this version:}

Jean-Jacques Lemaire, Anna Sontheimer, Hachemi Nezzar, Bénédicte Pontier, Jacques Luauté, et al.. Electrical modulation of neuronal networks in brain-injured patients with disorders of consciousness: A systematic review. Annales Françaises d'Anesthésie et de Réanimation, 2014, 33 (2), pp.88 - 97. 10.1016/j.annfar.2013.11.007 . hal-01577854

\section{HAL Id: hal-01577854 https://hal.science/hal-01577854}

Submitted on 28 Aug 2017

HAL is a multi-disciplinary open access archive for the deposit and dissemination of scientific research documents, whether they are published or not. The documents may come from teaching and research institutions in France or abroad, or from public or private research centers.
L'archive ouverte pluridisciplinaire HAL, est destinée au dépôt et à la diffusion de documents scientifiques de niveau recherche, publiés ou non, émanant des établissements d'enseignement et de recherche français ou étrangers, des laboratoires publics ou privés. 


\section{Electrical modulation of neuronal networks in brain-injured patients with disorders of consciousness: A systematic review}

\section{Modulation électrique de réseaux neuronaux de patients cérébro- lésés avec trouble de la conscience : revue de la littérature}

Jean-Jacques Lemaire ${ }^{\mathrm{a}, \mathrm{b}, *}$, Anna Sontheimer ${ }^{\mathrm{a}, \mathrm{b}}$, Hachemi Nezzar ${ }^{\mathrm{a}, \mathrm{c}}$, Bénédicte Pontier ${ }^{\mathrm{a}, \mathrm{d}}$, Jacques Luauté $^{\mathrm{e}}$, Basile Roche ${ }^{\mathrm{a}}$, Thierry Gillart ${ }^{\text {a,f }}$, Jean Gabrillargues ${ }^{\mathrm{a}, \mathrm{g}}$, Sarah Rosenberg ${ }^{\text {a,h }}$, Catherine Sarret $^{\mathrm{a}, \mathrm{i}}$, Fabien Feschet ${ }^{\mathrm{a}}$, François Vassal ${ }^{\mathrm{a}, \mathrm{j}}$, Denys Fontaine ${ }^{\mathrm{a}, \mathrm{k}}$, Jérôme Coste ${ }^{\mathrm{a}, \mathrm{b}}$

a. IGCNC - EA 728, Image-Guided Clinical Neuroscience and Connectomics, université d'Auvergne, Clermont université, hôpital Gabriel Montpied, 2e étage, HC; 58, rue Montalembert, 63003 ClermontFerrand, France

b. Service de neurochirurgie, hôpital Gabriel-Montpied, CHU Clermont-Ferrand, 58, rue Montalembert, 63003 Clermont-Ferrand, France

c. Service d'ophtalmologie, hôpital Gabriel-Montpied, CHU Clermont-Ferrand, 58, rue Montalembert, 63003 Clermont-Ferrand, France

d. Service de médecine physique et de réadaptation, hôpital Gabriel-Montpied, CHU de ClermontFerrand, 58, rue Montalembert, 63003 Clermont-Ferrand, France

e. Service de médecine physique et de réadaptation, hospices civils de Lyon, 3, quai des Célestins, BP 2251, 69229 Lyon cedex 02, France

f. Service de réanimation médico-chirurgicale, hôpital Gabriel-Montpied, 58, rue Montalembert, 63003 Clermont-Ferrand, France

g. Unité de neuroradiologie, hôpital Gabriel-Montpied, 58, rue Montalembert, 63003 Clermont-Ferrand, France

h. Unité d'électroencéphalographie et d'exploration fonctionnelle en neurologie, hôpital GabrielMontpied, 58, rue Montalembert, 63003 Clermont-Ferrand, France

i. Service de neuropédiatrie, hôpital Gabriel-Montpied, CHU de Clermont-Ferrand, 58 rue Montalembert, 63003 Clermont-Ferrand, France

j. Service de neurochirurgie, CHU de Saint-Étienne, 42055 Saint-Étienne, FrancekService de neurochirurgie, CHU de Nice, 06006 Nice cedex 1, France

* Corresponding author : jjlemaire@ chu-clermontferrand.fr 
Abstract

Six clinical studies of chronic electrical modulation of deep brain circuits published between 1968 and 2010 have reported effects in 55 vegetative or minimally conscious patients. The rationale stimulation was to activate the cortex through the reticular-thalamic complex, comprising the tegmental ascending reticular activating system and its thalamic targets. The most frequent intended target was the central intralaminar zone and adjacent nuclei. Hassler et al. also proposed to modulate the pallidum as part of the arousal and wakefulness system. Stimulation frequency varied from $8 \mathrm{~Hz}$ to $250 \mathrm{~Hz}$. Most patients improved, although in a limited way. Schiff et al. found correlations between central thalamus stimulation and arousal and conscious behaviours. Other treatments that have offered some clinical benefit include drugs, repetitive magnetic transcranial stimulation, median nerve stimulation, stimulation of dorsal column of the upper cervical spinal cord, and stimulation of the fronto-parietal cortex. No one treatment has emerged as a gold standard for practice, which is why clinical trials are still on-going. Further clinical studies are needed to decipher the altered dynamics of neuronal network circuits in patients suffering from severe disorders of consciousness as a step towards novel therapeutic strategies.

Résumé

Six études cliniques de modulation électrique chronique de circuits cérébraux profonds, publiées entre 1968 et 2010, ont rapporté des effets chez 55 patients, végétatifs ou en état de conscience minimale. Le rationnel de stimulation était d'activer le cortex par le complexe réticulo-thalamique comprenant le système réticulaire activateur ascendant tegmental et ses cibles thalamiques. La cible la plus fréquemment visée était la zone centrale intra laminaire du thalamus et les noyaux adjacents. Hassler et al. ont aussi proposé de moduler le pallidum, partie du système d'éveil et de vigilance. La fréquence de stimulation variait de $8 \mathrm{~Hz}$ à $250 \mathrm{~Hz}$. La plupart des patients se sont améliorés, bien que de manière limitée. Schiff et al. ont démontré un lien entre l'apparition de comportements d'éveil et conscients et stimulation du thalamus central. D'autres traitements ont pu améliorer cliniquement le patient : médicaments, stimulation magnétique transcrânienne répétée, stimulation du nerf médian, stimulation des cordons postérieurs de la moelle cervicale et stimulation du cortex frontopariétal. Aucun traitement n'a été validé pour la clinique courante, d'où la réalisation d'études cliniques, enregistrées, en cours. De nouvelles études sont nécessaires pour décrypter les altérations de la dynamique des circuits neuronaux chez des patients souffrant de troubles de la conscience sévères, permettant ainsi de proposer de nouvelles stratégies thérapeutiques.

Keywords: Deep brain stimulation; Consciousness; Thalamus; Neuromodulation; Brain injury Mots clés: Stimulation cérébrale; Conscience; Thalamus; Neuromodulation; Dommage cérébral 
Deep brain stimulation (DBS) is a validated treatment for severe symptoms refractory to optimal drug trials. It involves modulating altered neuronal brain circuits by chronic electric stimulation, placing electrodes in the brain, in thalamic nuclei or basal ganglia. The DBS story highlights the tortuous route taken by the medical community to assimilate the technique [1]. Be that as it may, DBS is now proposed as a way to alleviate extrapyramidal motor disorders such as tremor, dyskinesia, rigidity and dystonia [24], and research is on-going to explore or validate further indications such as depression, obsessive compulsive disorder, pain, obesity, anorexia and epilepsy [5-7].

The aim of DBS in patients with severe post-brain injury disorders of consciousness is to restore communication and goal-directed behaviour. However, DBS brings a number of challenges: we do not yet master all the aspects of the brain networks engaged in consciousness processing, and there is the hypothesis that DBS could overdrive neuron activity promoting plasticity within residual, partially damaged, and also undamaged but dysfunctional, circuits. Injury involves multiple mechanisms that are often combined, such as trauma, haemorrhage, ischemia, epilepsy, hydrocephalus and anoxia, and so prospective patients liable to benefit from DBS for severe, chronic or sometimes long-term disorders of consciousness fall into a wide range of individual phenotypes. Consciousness disorders follow a clinical progression of recovery: coma, where the eyes remain closed; vegetative state, where the eyes open but there is no observable conscious goal-directed behaviour; and minimally conscious state (MCS), where the patient shows inconsistent but discernible evidence of consciousness [8]. Emergence from MCS is achieved when the patient fully communicates, whatever the severity of the remaining disability [9]. The European Task Force on Disorders of Consciousness recently passed a proposal rename persistent vegetative state as unresponsive wakefulness syndrome[10]. The Liège group, which participates actively in defining these clinical states, has proposed two MCS subcategories [11]: MCS+, patients following commands, intelligible verbalization and gestural or verbal yes/no responses, and MCS-, patients demonstrating pursuit eye movement, ability to localize (and orient) noxious stimuli, and appropriate movements or affective behaviours. There is also a growing body of evidence that we can learn more about consciousness-related brain function from functional magnetic resonance imaging (fMRI) than from clinical observation (see [12] for a review). This new ability to explore covert behaviours combined with recent advances in neural correlates is expected to yield further insight into the phenomenology of consciousness applied to clinical phenotypes [13]. On-going research hopes to decipher the intimate mechanisms and circuits supporting the emergence of consciousness.

The goal of this systematic review is to summarize key data from all the clinical DBS trials that aimed to alleviate post-brain injury disorders of consciousness - three case reports [14-16], two observational series [17-21] and one crossover study [22] published between 1968 and 2010. The thalamus, tegmentum and pallidum were targeted for electrode implantation (Table 1) as the thalamus and tegmentum belong to the reticular-thalamic activating complex involved in arousal and consciousness [23-25] and as pallidum stimulation provokes arousal in cats and human $[15,26]$. Methodology and results are given for each series, and discussion is consolidated in an attempt to propose realistic medical perspectives. 
Table 1. Targeting and location of electrodes implanted in patients suffering from severe disorders of consciousness post-brain injury.

\begin{tabular}{|c|c|c|c|c|c|c|}
\hline \multicolumn{3}{|c|}{ Study } & Intended location & \multicolumn{2}{|c|}{ Anatomic target } & \multirow[t]{2}{*}{ Electrode location } \\
\hline Year & Patients & Hemisphere & & & & \\
\hline $\begin{array}{l}\text { McLardy et } \\
\text { al., } 1968\end{array}$ & 1 & $\begin{array}{l}\text { Unilateral } \\
\text { left }\end{array}$ & Intralaminar nuclei & and mesencephalic & reticular formation & $\begin{array}{l}\text { Neuropathology: left electrode } \\
\text { was located in the rostral nucleus } \\
\text { reticularis, ventral anterior } \\
\text { nucleus, paracentral nucleus and } \\
\text { centromedian parafascicular } \\
\text { nucleus complex (CMPf), then } \\
\text { traversed the red nucleus to } \\
\text { reach the reticular formation of } \\
\text { the lower midbrain terminating } \\
\text { in the raphe tegmental }\end{array}$ \\
\hline \multirow[t]{2}{*}{$\begin{array}{l}\text { Hassler et } \\
\text { al., } 1969\end{array}$} & 1 & Left & $\begin{array}{l}\text { Anterior central } \\
\text { thalamus }\end{array}$ & $\begin{array}{l}\text { Sagittal diagram of } \\
\text { thalamus, } 6.5 \mathrm{~mm} \\
\text { from midline; } \\
\text { Schaltenbrandt \& } \\
\text { Bailey atlas }\end{array}$ & $\begin{array}{l}\text { Tip in the base of the } \\
\text { ventral anterior } \\
\text { thalamic nucleus } \\
\text { (Lpo. i) and thalamic } \\
\text { fascicle (H1). The } \\
\text { other contact is } \\
\text { located in the upper } \\
\text { part of VA } \\
\text { belonging to Lpo.'s }\end{array}$ & n.a. \\
\hline & & Right & \multicolumn{3}{|l|}{ Pallidum } & \\
\hline $\begin{array}{l}\text { Sturm et al., } \\
1979\end{array}$ & 1 & Left & \multicolumn{3}{|c|}{ Nucleus reticulatus polaris thalami } & \multirow{2}{*}{$\begin{array}{l}\text { Neuropathology: left electrode } \\
\text { was located in the ventricular } \\
\text { foramen touching the } \\
\text { anteromedial aspect of the } \\
\text { thalamus at the nucleus } \\
\text { reticulatus polaris thalami }\end{array}$} \\
\hline & & Right & \multicolumn{3}{|c|}{ Rostral part of the lamella medialis thalami } & \\
\hline $\begin{array}{l}\text { Cohadon et } \\
\text { al., } 1985\end{array}$ & 6 & $\begin{array}{l}\text { Unilateral } \\
\text { right }\end{array}$ & $\begin{array}{l}\text { Centromedian } \\
\text { nucleus of the } \\
\text { thalamus }\end{array}$ & \multicolumn{2}{|c|}{ Atlas by Talairach et al. } & n.a. \\
\hline $\begin{array}{l}\text { Tsubokawa } \\
\text { et al., } 1990\end{array}$ & 2 & \multirow{3}{*}{ n.a. } & \begin{tabular}{|l|} 
Nucleus \\
cuneiformis of the \\
mesencephalic \\
reticular formation \\
\end{tabular} & \multicolumn{2}{|c|}{$\begin{array}{l}\text { Dorsal part of the nucleus ruber and } \\
\text { ventral part of the deep layer of the } \\
\text { superior colliculus according to } \\
\text { Olszewski and Baxter atlas }\end{array}$} & n.a. \\
\hline & 6 & & Centromedian & \multirow{2}{*}{\multicolumn{2}{|c|}{$\begin{array}{l}\text { Posterior, } 7-9 \mathrm{~mm} \text {; lateral, } 5-6 \mathrm{~mm} \text {; } \\
\text { height, } 0-1 \mathrm{~mm} \text {; anterior commissure - } \\
\text { posterior commissure landmarks }\end{array}$}} & \\
\hline $\begin{array}{l}\text { Yamamoto } \\
\text { et al., 2003- } \\
2010\end{array}$ & $-\begin{array}{l}26(18 \\
\text { new })\end{array}$ & & $\begin{array}{l}\text { parafascicular } \\
\text { nucleus complex } \\
\text { of the non-specific } \\
\text { thalamus }\end{array}$ & & & n.a. \\
\hline \begin{tabular}{|l} 
Cohadon et \\
al., 1993 \\
\end{tabular} & $\begin{array}{l}25(19 \\
\text { new })\end{array}$ & $\begin{array}{l}\text { Unilateral } \\
\text { right }\end{array}$ & & $\begin{array}{l}\text { Talairach et al. } \\
\text { atlas }\end{array}$ & & n.a. \\
\hline \multirow[t]{2}{*}{\begin{tabular}{|l} 
Schiff et al., \\
2007
\end{tabular}} & \multirow[b]{2}{*}{1} & \multirow[b]{2}{*}{ Bilateral } & \multirow{2}{*}{\multicolumn{3}{|c|}{$\begin{array}{l}\text { In the anterior intralaminar thalamic nuclei and adjacent } \\
\text { paralaminar regions of thalamic association nuclei. Each of } \\
\text { the four individual contacts were located within the central } \\
\text { lateral nucleus, paralaminar regions of the median dorsalis, } \\
\text { and the posteromedial aspect of the centromedian } \\
\text { parafascicularis nucleus complex. maximised coverage of } \\
\text { thalamic regions with strong calbindin protein staining }\end{array}$}} & MRI control: thalamus \\
\hline & & & & & & $\begin{array}{l}\text { DBS-EEG evoked potentials } \\
\text { showed that the right electrode } \\
\text { was more lateral, the superior } \\
\text { contact being close to } \\
\text { somatosensory relay nuclei }\end{array}$ \\
\hline
\end{tabular}

n.a.: not available. 


\section{The literature from 1968 to 2010}

McLardy et al. [14] reported the very first case of DBS in 1968, in a vegetative 19-year-old male, implanted about 8 months after head injury. They intended to place one electrode in the intralaminar thalamic nuclei and the reticular formation of the midbrain, in the left hemisphere. Stimulation frequency was $250 \mathrm{~Hz}$. Only the effects of the midbrain contacts were reported: left orientation of the head, movements of the left hand, and slight modifications of the electroencephalogram (EEG). The electrode was removed one month later. The patient died of infectious disease two years later, and the autopsy showed that the electrode went through the thalamus, crossing the rostral nucleus reticularis, ventral anterior nucleus, paracentral nucleus and centromedian parafascicular nucleus complex (CMPf), then through the red nucleus to reach the reticular formation of the lower midbrain and terminating in the raphe tegmental area (Table 1). The lesions predominated within the right-hemisphere cortex and the left and right thalamus.

Hasler et al. [15] then published a DBS case in 1969 of a 26-year-old male implanted about 5 months after head injury. The patient was in vegetative state, and sleep-waking cycles were clinically observed. The terms apallic patient, coma vigil and akinetic mutism were used due to the apparent loss of neocortical function, no reproducible evidence of intentional behaviour, and the fact the patient did not speak [27]. He was stimulated bilaterally - the intention was to place the left electrode in the anterior thalamus and the right electrode in the pallidum. Unilateral-acute, low-frequency (left electrode, $50 \mathrm{~Hz}$; right electrode, 8 $\mathrm{Hz}$ ), 15-minute stimulations 3 to 4 times per day provoked eyelid and eye movements with a post effect up to $20 \mathrm{sec}$. Stimulation of the right pallidum was associated with sporadic contralateral arm movements, and bilateral acute stimulations provoked stronger effects plus head movements following the eyes. Convulsive seizures sometimes occurred during thalamic stimulations up to $100 \mathrm{~Hz}$. The patient improved during the 19-day follow-up, showing apparently purposeful gaze and mimics, left arm and leg movements, head movements sometimes oriented toward relatives and unintelligible vocalization after tracheotomy removal. EEG frequencies increased during acute thalamic stimulation, especially under thalamic and pallidal bilateral acute stimulation. The electrodes were removed when broken. At the end of the 19-day follow-up, EEGs showed a reduction of right-left asymmetry and an abolished left delta focus.

Sturm et al. [16] reported a DBS case in 1979 of a 68-year-old male implanted about 1 month after the rupture of a basilar artery aneurysm and surgical clipping. The patient was likely vegetative. He was stimulated bilaterally within the thalamus - the intention was to place the left electrode in the nucleus reticulatus polaris thalami and the right electrode in the rostral part of the lamella medialis thalami. Only the left electrode was tested at chronic levels, as there was no clinical effect with the right electrode. 50$\mathrm{Hz}$ stimulation was performed daily for 10 min every hour. Acute effects were observed with a long post effect up to $10 \mathrm{~min}$ : transitory respiratory arrest at 8-10 Volts, peristaltic activity and purposeful responses (showing the tongue, lifting the arm and leg) at 6-7 volts. During the four weeks of stimulation, the patient improved toward verbal contact, sitting in a chair, oral feeding, and sleep-waking periods, with improved general status (body temperature, pulmonary infection resolved). Persistent non-reactive alpha 
EEG activity shifted to a less monotonous activity with theta and delta waves. The patient died of unreported cause two months after hospitalization. The neuropathology findings showed extended ischemic basal lesions from tegmentum to striatum, thalamus and hypothalamus, and the tip of the left electrode was located in the ventricular foramen touching the anteromedial aspect of the thalamus at the nucleus reticulatus polaris thalami.

Cohadon et al. [17,18] published reports in 1984 and 1985 on the first series of 6 vegetative patients implanted 6 to 15 months after traumatic brain injury. Electrodes were intended to be placed in the centromedian nucleus of the right thalamus. Three patients showed no improvement during a 2-month DBS period, the electrodes were removed, and no further improvement was noted up to 2.5 years after the DBS trial. Three patients showed improvements inside 2 months: oral feeding, reduced pulmonary infection and bronchial secretion, limited goal-behaviour (at 2 to 4 weeks post-implant), slight improvement in tonic disturbance. The Bordeaux-based team then reported the whole series of 25 (23 trauma) neurovegetative patients in 1993 [19]. In the wake of the first series [17,18], they considered nonresponse after DBS could be an argument for definitive chronic vegetative status, and so after securing national ethical review board approval, they continued to implant patients, starting at the 3rd month postinjury in cases showing no clinical evolution. Intended target was slightly different, as this time they aimed for the CMPf. Electrical stimulation was performed continuously from 8 a.m. to 8 p.m., at $50 \mathrm{~Hz}$, after titration, i.e. determination of the voltage value just under the current triggering adverse effects, including reinforced hypertonic reactions. The period of observation was set at 2 months, after which DBS was stopped and the material was removed if there was no recorded improvement. Follow-up ranged from 1 to 12 years. The team assessed clinical evolution using two institutional functional scales - an early score and a late score. The early evaluation score, from 0 to 28 , comprised 4 sub-scores:

- vital signs, from 0 (hyperthermia, gastrostomy and bronchial hypersecretion) to 7 (normothermia, liquid deglutition, and no respiratory disturbance);

- $\quad$ arousal and communication, from 0 (no eye opening) to 7 (verbal responses);

- muscular tonus, from 0 (head and trunk hypotonia, major limb hypertonia, and more than 4 hypertonic crises per day) to 7 (sitting without help, normal limb tonus, and no tonic crises);

- motility, from 0 (zero motility) to 7 (emotional mimics and elaborate goal-oriented movements).

The late evaluation score, from 0 to 28 , also comprised 4 sub-scores:

- daily life, from 0 (no sphincter control, entirely dependent on feeding assistance and lack of initiative) to 7 (diurnal sphincter control, no feeding assistance, and autonomy initiatives);

- cognitive status, from 0 (no language, memory or reasoning) to 7 (normal language, memory, reasoning);

- axial motility, from 0 (bedridden) to 7 (able to walk);

- goal-directed movement, from 0 (tetraplegia) to 7 (normal). 
The global early-plus-late functional score thus ranged from 0 to 56. The team also measured the final handicap using two more institutional scales: the neurological score capturing verbal communication, cognitive functions and autonomy, and the reinsertion score capturing environment and activities of daily living. Thirteen (out of 25;52\%) patients demonstrated significant improvement in global functional score between 2 weeks and 2 months after DBS was started. The average global functional score of the 13 responders progressively increased from 10 to 40, with each sub-score showing parallel improvements, whereas the 12 non-responders remained at about 10 . The responders were significantly slightly younger (17.8 vs. 28 year-old). All the responders became communicative. They measured concentration of brain metabolites in cerebrospinal fluid in 3 patients, and found that 5-Hydroxyindoleacetic acid (5-HIAA; serotonin metabolite) and met-enkephalin (opioid growth factor) increased from a few hours after starting DBS-on periods and even post-DBS-on period in one case. The long-term final handicap of the 13 responders was as follows: verbal communication was slow (8 patients), cognitive functions were severely (6 patients) or moderately ( 4 patients) damaged, and most were severely handicapped ( 8 patients in a wheelchair, 8-9 patients needing assistance, and 12 patients qualified as dependent). Four non-responders and two responders died during follow-up. Of the 11 responders who survived, 10 had severe handicap and one had moderate handicap (according to Glasgow Outcome Score). They did not find electrophysiological retrospectively predictive factors of good outcome, and 24-h quantitative EEG under DBS improved before clinical improvement [28].

Tsubokawa et al. [20] reported a DBS series in 1990 of 8 patients (4 traumas, 3 strokes, 1 anoxia; aged 22 to 75 years old; 5 males) implanted 6 months after primary cerebral injury. The intention was to place electrodes in the nucleus cuneiformis of the mesencephalic reticular formation ( 2 cases) and the CMPf of the non-specific thalamus (6 cases). The paper does not detail whether DBS was uni- or bilateral. Stimulation at $50 \mathrm{~Hz}$ was performed 2 hours. per day in 30-min periods. Clinical assessment was based on the institutional prolonged coma score (PCS), ranging from 1 (alive with spontaneous respiration) to 10 (verbal response). Prior to DBS, the 8 patients had a PCS ranging from 2 to 4 , i.e. spontaneous movement of extremities, and so were likely vegetative or MCS. A PCS increase to at least 8 (i.e. producing sounds) was considered excellent, to 5, i.e. pursuit eye movement, was considered slightly effective, and stagnant at $<5$ was ineffective. Acute effects were described in these 8 patients: open eyes with dilated pupils, open mouth and meaningless vocalization, slight increase in blood pressure and EEG arousal patterns. Other biological changes were also reported: suppression of intracranial pressure A waves and increased cerebral blood flow (10-72\%), metabolic rate of oxygen (10-40\%) and glucose uptake (200-300\%) measured by PET imaging (using 11CO2, $15 \mathrm{O} 2$ and 11C glucose, respectively). There was no increase in oxygen extraction fraction. Glucose uptake increased in both cortex and contralateral thalamus, with noneffective cases showing luxury perfusion in cortical areas and a slight increase in the stimulated area. 5HIAA and homovanillic acid (HVA; a catecholamine metabolite) levels increased in effective patients. At 12-month follow-up, treatment was rated excellent in 3 of the 8 patients, slightly effective in 1, and ineffective in 4 . The first increases in PCS were registered between 1 and 3 months post-DBS and all patients showed increased PCS at 5 months post-DBS. Since this first publication, the Tokyo group has continued to report on the series, giving long-term results and adding new patients - 20 cases in 2002 [29], 21 cases in 2003 [30], 26 cases in 2005 [31] and 21 cases in 2010 [21]. The team continued to stimulate the CMPf and stopped implanting electrodes in the mesencephalic reticular formation, considering the thalamus as safer and more widely connected to the cerebral cortex. Their last report of 21 vegetative 
patients [21] (aged 19 to 75 years, mean age: $43 \pm 20.1$ ) had a very long-term follow-up of over 10 years. DBS was started up 4 to 8 months post-injury (9 trauma, 9 stroke and 3 anoxia), at a frequency of $25 \mathrm{~Hz}$, which is lower than reported in their first series. Eight of the 21 patients $(38 \%)$ - all trauma and stroke victims - improved toward at least MCS, and one was even no longer bedridden. Improvement happened between 4 and 12 months after starting DBS, with no later change in clinical status. The 21 cases came from a series of 107 vegetative patients, and the 86 non-DBS patients had similar ages and aetiologies of injury. The team retrospectively studied a subgroup of 16 patients (10 implanted) presenting electrophysiological signs (5th wave of the auditory brainstem and N20 wave) and observed that 8 of the 10 DBS patients but none of the 6 non-implanted patients recovered $(\mathrm{P}<0.01)$.

Schiff et al. [22] reported a case study of a 38-year-old MCS male implanted 6 years after traumatic brain injury. The patient had been explored 2 years earlier using fMRI, which revealed evidence of covert language activity [32]. They bilaterally implanted the anterior thalamus, intending to place the electrodes in the anterior intralaminar thalamic nuclei and adjacent paralaminar regions of thalamic association nuclei. The titration phase looked for adverse effects and behavioural changes, starting about 7 weeks post-implant and lasting 4.5 months. At 6 months post-implant, a 6-month double-blinded alternating on/off crossover phase (continuous on and off periods changed every month) was started up, with stimulation frequency set to $100 \mathrm{~Hz}$. All routine rehabilitation activities (physical, occupational, speech and recreational therapies) were maintained throughout the entire study. The primary outcome measures were the JFK Coma Recovery Scale - Revised [33] (CRS-R; from 0 [no function] to 23 [full recovery]) and three subscales (out of 6): an arousal subscale (CRS-R-A; 0 unarousable, 1 eye opening with stimulation, 2 eye opening without stimulation, 3 attention), a motor subscale (CRS-R-M; 3 out of 7 scores: 4, object manipulation, 5 automatic motor response, 6 functional object use), and a communication/oromotor - verbal subscale (CRS-R-O, 2 out of 4 scores: 2 vocalization/oral movement; 3 intelligible verbalization). Three secondary outcome measures were added (institutional scales): object naming [from 1, Intelligible, to 5, no response]; purposeful upper extremity limb movement [from 1, full execution, to 5, no response]; oral feeding [from 1, normal manipulation of bolus, to 5, oral feeding is refused]. During DBS-on periods, patients generally reached the maximal score on the CRS-R-A scale, and there were improvements in purposeful upper extremity limb movement and oral feeding. The study was competed with logistic regression analysis that strongly suggested nearly all of the systematic changes in ratings were temporally linked to DBS stimulation. During the titration phase, improvements in intelligible verbalization and limb control were linked to the DBS-on condition. After the crossover period, the patient showed further improvement in oral feeding and communication, whereas active and passive ranges of movement decreased due to increased spasticity. DBS-EEG evoked potentials on postoperative day 2 showed different effects of right and left DBS electrodes: a proximal (superior) contact (\#3) of the left electrode evoked a strong response over the dorsal and midline bifrontal cortex, whereas one the two distal (inferior) contacts (\#1) of the right electrode evoked a weak ipsilateral response over the most lateral scalp EEG cup electrodes. 


\section{Analysis and prospects}

Despite small-sized series samples, different DBS settings, different times to implant after injury and outcome assessments, the evidence suggests DBS could promote recovery in brain-injured patients with disorders of consciousness. All the results, bar the very first attempted DBS by McLardy et al. [14], show limited but measurable improvement in patient conditions in most cases. The main concern is methodology weaknesses in most reports, as observational studies deliver a low grade of evidence [34]. Furthermore, the technology was still fairly rudimentary when the first reports were published, with no implantable device available for long-term chronic DBS [14-16] and first-generation electrodes that had a non-coaxial stylet pulling the electrode into the brain [17,20]. Finally, postoperative analysis of effective contact location is not available. In most patients, it is difficult to differentiate DBS effect from spontaneous and/or post-rehabilitation (wide meanings) recovery. Only recently, Schiff et al. [22] demonstrated that thalamic DBS directly provokes fluctuations in arousal and conscious behaviours.

In broadly terms, taking the two series of the Bordeaux and Tokyo groups [19,21], we can deduce that $38 \%$ (8 out of 21) to 52\% (13 out of 25) of vegetative or MCS patients can improve, but only one patient (out of 46; about 2\%) was no longer bedridden. From 1985, poor results prompted Cohadon et al. [18] to remain cautious over a technique that only offered "half-way recovery", and even now, 28 years later, there is still a host of unresolved issues for future clinical trials, notably to determine the most effective functional deep brain target(s), optimal stimulation parameters, and candidate responder selection criteria. It is particularly important to be able to screen the responders for the best candidates liable to gain substantial benefit from DBS, - although what 'substantial' means for this patient population needs to be defined with care and revised continually in response to on-going clinical, research and societal advances.

\subsection{DBS targets to alleviate altered arousal and conscious behaviours}

Although disparate, study results nevertheless converge to suggest that DBS of the thalamus, tegmentum or pallidum can trigger arousal and conscious behaviours, with the thalamic reticular activating system involved in arousal and consciousness [23-25] and the pallidum involved in arousal $[15,26]$.

The thalamic reticular activating system comprises the ascending reticular activating system (ARAS) and its thalamic targets, chiefly intralaminar nuclei connected mainly through the central tegmental tract [35]. The thalamic reticular complex connects to the overall cortex and striatum [35-39]. The intralaminar nuclei are part of a so-called non-specific thalamus also involving the lateral posterior, ventral posterior, ventral anterior and ventral lateral nuclei [35]. The centromedian parafascicular nucleus complex (CMPf) of the posterior intralaminar nuclei is a key structure in motor, associative-limbic and integrative circuits 
at the crossroads of basal ganglia, particularly striatum, brainstem and cortex in primates [40]. Schiff [41] captured this key role of the thalamus in arousal and consciousness disorders by proposing the notion of central thalamus for the anterior and posterior intralaminar nuclei plus paralaminar portions of related thalamic-associative dorsomedial, ventral anterior, ventral lateral and inferior pulvinar nuclei. The reticular thalamus, stratum and nucleus wrapping the thalamus should be involved in attention, the prerequisite to consciousness, filtering stimuli like a gateway to the cortex [42-44]. The case report by Sturm et al. [16] supports this hypothesis. The ARAS is also connected to the zona incerta, hypothalamus and limbic nuclei. The main ARAS inputs come from spinoreticular projections and sensory cranial nerves [35]. The mesencephalic ARAS nuclei cover an array of structures, such as the cuneiform (cuneiformis) nucleus, pedunculopontine (tegmenti pedunculopontinus) nucleus, and locus coeruleus. The pontomesencephalic Duret haemorrhage is an example of focal lesion in the thalamic reticular activating complex that provokes coma [45]. Recent work on basal ganglia bring further evidence that the putamen and pallidum are involved in arousal and consciousness [46,47]. Cholinergic, noradrenergic, histaminergic, dopaminergic and serotoninergic circuits within the basal forebrain, basal ganglia, hypothalamus and brainstem are also directly or indirectly involved - in this case mainly through the thalamus - in the physiology of arousal and wakefulness (see [25] for a review). Schiff et al. [22] intended to place the electrode contacts in the central lateral nucleus, paralaminar regions of the median dorsalis, and posterior medial aspect of the CMPf nucleus complex in an effort to maximize coverage of thalamic regions with strong calbindin protein staining. Calbindin staining involves almost all the thalamic nuclei (except the superficial reticular thalamus), which project mainly to superficial cortical layers [48-50]. The central lateral nucleus itself connects to the thalamic reticular nucleus, striatum and cortical layers [51,52], as do the CMPf nucleus complex and other intralaminar nuclei [35]. Experiments in mice have shown that the central lateral nucleus and ventrobasal nucleus co-operate to modulate the thalamocortical loops involved in temporal binding synchronizing cortical neuronal discharges [51].

The list of all the anatomic targets in implanted patients covers a wide portion of the thalamus (Table 1). Fig. 1 summarizes the anatomy of the thalamo-tegmental target areas and the thalamic anatomic regions potentially involved in consciousness processing, as inferred from the literature. The severe and sometimes extended deep brain lesions in severe chronic disorders of consciousness combined with the resulting anatomical restructuring is a major factor to weigh up when considering the intended targets as a real location of contact electrodes. In parallel to this context of major brain lesions, from a surgical standpoint, stereotactic atlases offer only limited aid for primary anatomic targeting. 


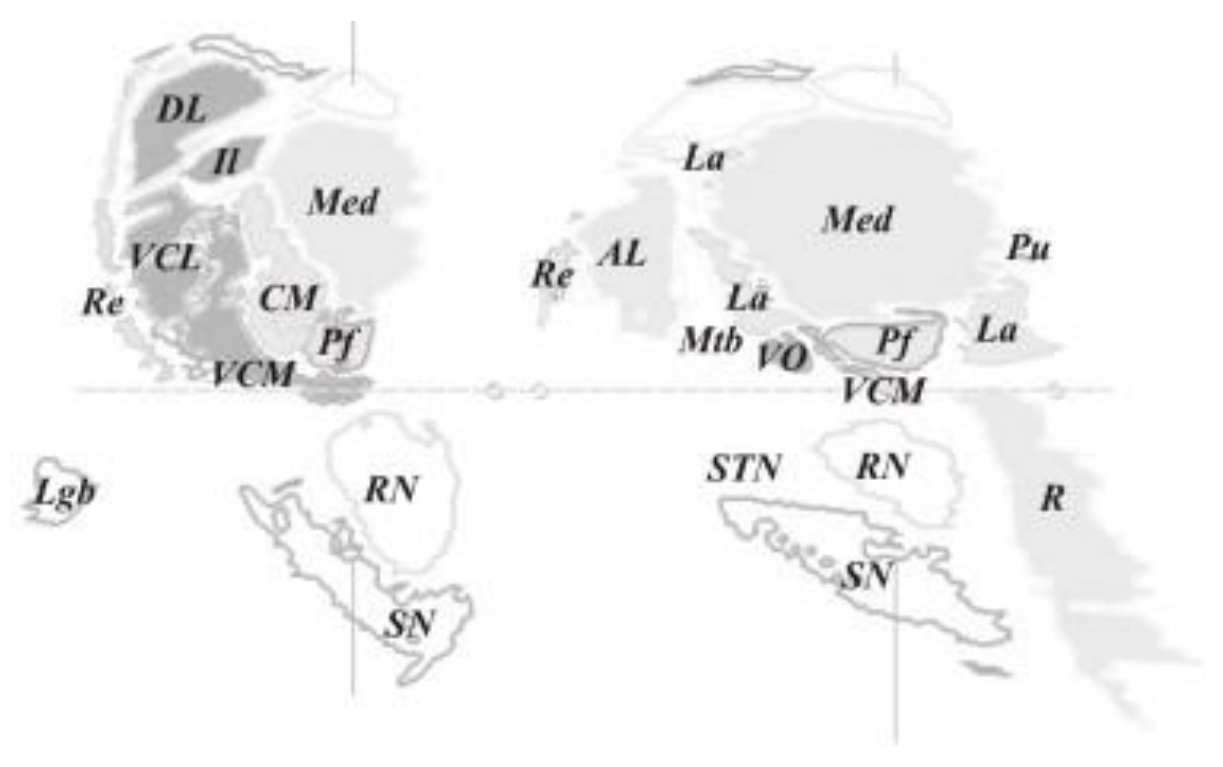

Figure 1. Thalamo-tegmental structures intended to be targeted (light grey) and other thalamic nuclei involved in consciousness processing (dark grey). Semi-schematic representation from Lemaire et al. [93] with the red nucleus (RN), substantia nigra (SN), mammillothalamic bundle (Mtb) and anterior commissure - posterior commissure (ACPC) line (dotted); left, coronal section going through the lateral geniculate body (Lgb); right, sagittal section, $6.5 \mathrm{~mm}$ lateral to the ACPC plane; for terminology, see [93]: anterolateral (AL) nucleus including the largest aspect of the ventral anterior nucleus; reticular nucleus (Re); intralaminar nuclei (La) including the centromedian nucleus (CM) and the parafascicularis nucleus (Pf); ventrocaudal lateral (VCL) and ventrocaudal medial (VCM) nuclei of the group of ventral posterior nuclei, which involves the ventrobasal nucleus; ventro-oral (VO) nucleus of the ventral lateral nuclei; dorsolateral (DL) nucleus and intermediolateral (Il) nucleus forming the two aspects of the lateral posterior nucleus of thalamus; reticular tegmental area (R); medial or dorsomedial (Med) nucleus; pulvinar $(P u)$.

\subsection{Non-DBS targets and improvement of altered arousal and conscious behaviours}

Neuromodulation of consciousness-related circuits is also proposed for various therapies applied to nonthalamic regions. Like most DBS studies, most non-DBS studies suffer weak methodology.

External sensory stimulations to non-specific brain systems are widely used in clinical routine to stimulate brain-injured patients, yet analysis of literature failed to find proven clinical efficacy [53]. Electrical stimulation of the dorsal columns of the spinal cord is one way to non-specifically increase these inputs. Chronic stimulation of the dorsal column of the upper cervical spinal cord was realized in a large observational series of persistent vegetative patients using alternate 15-min ON/OFF periods during daytime (extradural, bipolar, $70 \mathrm{~Hz}$ ), with excellent (purposeful response) and positive (emotional response, visual attention, eyelid reaction to stimuli) results in 109 patients (out of 213, minus 13 lost to 
follow-up; 54\%) [54]. Yamamoto et al. [55] recently reported an observational series of 10 MCS patients treated 3 to 53 months post-injury, also with chronic stimulation of the upper cervical dorsal column (5$\mathrm{Hz}, 5$ min every 30 min during daytime), where 8 of the 10 patients emerged from MCS over a 1-year follow-up period. Vagus nerve stimulation is another way to simultaneously stimulate several brain regions, particularly non-specific systems [56]. It has been proposed in comatose patients [57], and it currently being trialled in a crossover study designed to assess recovery from MCS or PVS after traumatic brain injury (clinicaltrials.gov/ NCT01260090). In 1999 [58], bottom-up stimulation of the brain with repetitive stimulation of the median nerve (rMNS) showed that early use of rMNS in the intensive care unit could shorten stay and improve patient outcomes at 1 month. RSM and/or hyperbaric oxygen was also performed in a series of 41 brain-injured patients ( 25 trauma, 11 stroke and 5 hypoxia) after discharge from the intensive care unit [59]: combined rMNS plus hyperbaric oxygen was more likely to increase cerebral perfusion and improve Glasgow coma score in stroke and hypoxia patients whereas trauma patients were more likely to benefit from rMNS only. A case study testing repetitive transcranial magnetic stimulation (rTMS) against rMNS found that rTMS could be more efficient [60].

The rationale for fronto-parietal cortex stimulation is based on models of the physiological large-scale networks supporting consciousness (see e.g. [61,62]) and, in pathology, the persistence activity of functional cortical areas involved in awareness in PVS patients [63]. Extradural fronto-parietal chronic electric stimulation was performed in a 19-year-old PVS female 2.5 years after a traumatic brain injury [64]. The left hemisphere was covered by two 4-contact electrodes from the middle frontal gyrus (up to the polar region) to the intraparietal gyrus between the superior and inferior parietal gyrus. The $8-10 \mathrm{~Hz}$ bipolar stimulation of the two electrodes was associated with clinical modifications in arousal, tone and vegetative parameters within 12 hours after starting stimulation, and over the 10-month follow-up period, CRS-S increased from 4 to 8 (by 1 unit per month), and spasticity improved. Note that the improvement dulled when the battery ran down and then picked up again when the battery was replaced. Cortical stimulation has also been performed with rTMS in a 26-year-old male remaining vegetative about 10 months after traumatic brain injury [65]. After a 6-week rTMS protocol of the right dorsolateral prefrontal cortex (30 sessions per day, 5 days per week), no adverse effect was observed and a Disorders of Consciousness Scale found a non-significant trend of neurobehavioral gains [66].

\subsection{Drugs, arousal and conscious behaviours}

Drug therapies have been proposed in comatose, vegetative, MCS and disabled patients to improve disorders of consciousness and residual cognitive impairments, including L-Dopa [67,68], amphetamine, methylphenidate and bromocryptin [69], subcutaneous apomorphine [70], zolpidem, baclofen, dopamine agonists and tricyclic antidepressants [71], and amantadine [69,72]. Most are effective, with low to high grade of evidence [34], but there is still no consensus on their clinical use and on the definition of responders $[73,74]$. Intrathecal administration of gamma-aminobutyric acid agonists could also improve vegetative patients [75]. 


\subsection{Frequency dependence of clinical effects in DBS}

The frequency dependence of clinical effects in DBS is accepted without being fully understood [76,77]. Historically, the first report of Parkinsonian tremor suppression by chronic stimulation of the nucleus ventralis intermedius (VIM) of the thalamus [78] had shown that $100 \mathrm{~Hz}$ would be the lowest highfrequency stimulation (HFS) able to provoke lesioning-like clinical effects. A more recent study reported that stimulo-induced gait disturbance in severe Parkinson's disease is alleviated by switching subthalamic 130-Hz HFS to $60 \mathrm{~Hz}$ [79]. However, we still know little about the precise mechanism underpinning brain circuit modulation by chronic DBS and brain circuits in general. Nevertheless, cortical excitability increases with $185-\mathrm{Hz}$ VIM DBS [80], and $130-\mathrm{Hz}$ pallidal DBS for dystonia provokes a reduction of long-term potentiation-like motor cortex plasticity [81]. Recent experimental results in rats also show that 100-Hz HFS provokes cortico-subthalamic nucleus (STN) synaptic depression in dopamine-depleted STN [82]. DBS of the ventral posterolateral nucleus of the thalamus achieved the best results for alleviating severe chronic pain with frequencies ranging from 50 to $100 \mathrm{~Hz}$ [83].

Pioneering experiments in cats to exploring the mechanisms of arousal used acute stimulation wave trains to evoke remote potentials: HFS from $100 \mathrm{~Hz}$ to $250 \mathrm{~Hz}$ provoked remote activity [24], particularly arousal-like EEG activity [23], which was also observed at 50-Hz stimulation in the brainstem reticular formation [23]. DBS frequencies used in thalamus, tegmentum and pallidum stimulation in patients with consciousness disorders range from 8 to $250 \mathrm{~Hz}$. Clinical and experimental results on DBS are still not strong enough to infer the frequency dependence of clinical effects in patients with consciousness disorders, even though most patients are stimulated at low frequencies centred on $50 \mathrm{~Hz}$ (Table 2).

Table 2. Stimulation parameters and electrodes used in series reported from 1968 to 2010. Medtronic

(Medtronic Inc., Minneapolis, USA) electrodes are referenced (types 3380 and 3387).

\begin{tabular}{|c|c|c|c|c|c|c|c|c|}
\hline \multirow[t]{2}{*}{ Studies } & \multicolumn{4}{|c|}{ Stimulation parameters } & \multicolumn{4}{|c|}{ Electrode } \\
\hline & $\begin{array}{c}\text { Frequency } \\
(\mathbf{H z})\end{array}$ & $\begin{array}{l}\text { Pulse } \\
(\text { msec) }\end{array}$ & $\begin{array}{c}\% \text { of } \\
\text { stimulation } \\
\text { duration/sec }\end{array}$ & Volt & $\begin{array}{c}\text { Number of } \\
\text { contacts }\end{array}$ & $\begin{array}{c}\text { Electrode } \\
\text { type }\end{array}$ & $\begin{array}{c}\text { Contact dimensions } \\
\text { (mm): length; contact-to- } \\
\text { contact distance; } \\
\text { diameter }\end{array}$ & $\begin{array}{c}\text { Number of } \\
\text { contact used }\end{array}$ \\
\hline $\begin{array}{l}\text { McLardy et } \\
\text { al., } 1968\end{array}$ & 250 & 1 & 0.250 & \multicolumn{5}{|c|}{ n.a. } \\
\hline $\begin{array}{c}\text { Hassler et al., } \\
1969\end{array}$ & $\begin{array}{c}50 \\
\text { (thalamus) }\end{array}$ & 3 & 0.150 & 20 & 2 & n.a. & 2 (estimated); $6 ; 0.5$ & n.a. \\
\hline & 8 (pallidum) & 3 & 0.024 & 30 & & & & \\
\hline \begin{tabular}{|c|} 
Sturm et al., \\
1979 \\
\end{tabular} & 50 & 0.5 & 0.025 & 10 & 4 & 3380 & 1; 2; n.a. & \\
\hline \begin{tabular}{|c|} 
Cohadon et al., \\
1984.1985
\end{tabular} & & 5 & 0.250 & $5-10$ & & & & \\
\hline \begin{tabular}{|c|} 
Cohadon et al., \\
1993 \\
\end{tabular} & & & & $\begin{array}{c}0.005- \\
0.010 \\
\end{array}$ & $\begin{array}{c}4 \text { in most } \\
\text { cases }\end{array}$ & & & $\begin{array}{l}\text { Bipolar in } \\
\text { most cases }\end{array}$ \\
\hline \begin{tabular}{|c|}
$\begin{array}{c}\text { Tsubokawa et } \\
\text { al., } 1990\end{array}$ \\
\end{tabular} & & n.a. & n.a. & 10 & n.a. & & & \\
\hline $\begin{array}{c}\text { Yamamoto et } \\
\text { al., } 2010 \\
\end{array}$ & 25 & & & n.a. & 4 & $\begin{array}{c}3380 \& \\
3387\end{array}$ & & \\
\hline $\begin{array}{c}\text { Schiff et al., } \\
2007 \\
\end{array}$ & 100 & n.a. & n.a. & 4 & & 3387 & $1.5 ; 1.5 ; 1.3$ & Right, bipolar \\
\hline & & & & & & & & $\begin{array}{c}\text { Left, } \\
\text { monopolar }\end{array}$ \\
\hline
\end{tabular}

n.a.: not available. 
The Tokyo series has also demonstrated that low-frequency thalamic DBS globally increases the brain's consumption of energy [20,21,29-31], which is largely coupled with neuronal activity [84] regardless of whether functionality represents activation or inhibition. Dorsal column cervical spinal cord stimulation also appears to globally increase CBF [55], and the behavioural benefits obtained are better in patients with preoperative regional CBF values of over $20 \mathrm{~mL} / 100 \mathrm{~g} / \mathrm{min}$ [54].

\subsection{Future clinical trials}

Although heterogeneous and with mostly low grade evidence, the results of clinical trials do show that DBS is able to module severe post-injury disorders of consciousness. This is clearly not strong enough grounds to propose DBS as clinical routine, and there are several issues that will need to be resolved first. More rigorous trials are mandatory for the development of effective restorative treatments. There are four on-going registered studies aimed to alleviating post-injury consciousness disorders: 2 DBS (NCT01718249, NCT01027572), 1 vagus nerve stimulation (NCT01260090), and 1 amantadine (NCT00779324) study.

Future studies should also look further ahead to determine the key factors optimizing benefit, such as time after onset. For this purpose, future studies should separate the early, intermediate and chronic post-injury phases. The early phase covers the first three months. In most cases, this will mean ICU patients that require considerable assistance. This phase is surrounded by all sorts of issues, in particular the very difficult concern of withdrawal of life-sustaining therapies. If caregivers and the patient's surrogate decision makers agree to maintain care, it should be useful to potentiate and facilitate neuronal spontaneous recovery using targeted drugs and/or indirect physical means of brain network modulation such as rTMS or rMNS. The intermediate phase covers the period where spontaneous recovery can still occur, which in general will mean up to 1 year post-injury, although the extent is very difficult to anticipate $[85,86]$. More aggressive therapies could likely be proposed up to DBS and potentially with combined treatments (e.g. drugs and DBS) if the benefit-risk ratio is acceptable, with the same aim to potentiate and facilitate neuronal spontaneous recovery. The chronic phase covers the period where significant recovery, even if theoretically possible in the very long-term [87], is highly unlikely and about $40 \%$ of patients die within two years [85]. MCS patients appear more likely to show recovery, although with severe handicap [86]. This late period is particularly complex as it concerns the most severe patients with severely injured brains, and DBS studies to date have tended to focus on these cases.

Future research looks certain to exploit brain mapping techniques to better identify neural correlates of consciousness [11] and help identify favourable parameters of therapeutic response.

Any kind of research into new therapeutic strategies, governing by strict control of technical and ethical issues, is well warranted for these particularly vulnerable patients, as most of them - along with their relatives and caregivers - are without any kind of optimistic long-term perspective.

The covert activity demonstrated in patient series $[12,88,89]$ points to perspectives for the development of brain-computer interfaces [90] enabling communication with patients up to unresponsive wakefulness syndrome and maybe even coma. Further insight will likely deeply modify our understanding in these exceptionally delicate situations. 


\section{Conclusion}

DBS is a challenging therapeutic option for post-injury severe consciousness disorders, and must be weighed up in a context of the clinical course over time, from resuscitation to rehabilitation. The goal is to alleviate the "invisible barrier" blocking goal-oriented behaviours. However, in the brain injury setting, isolated consciousness disorder is still a fairly conceptual condition that relies heavily on the hypothesis of absence of extended brain lesions. This makes it absolutely vital to finally identify favourable prognostic factors, and the process will likely benefit from quantifying brain lesions and assessing neurophysiological parameters $[12,89,91]$. The goal is to detect residual brain circuits predictive of significant clinical benefit, i.e. emergence from PVS or MCS to full communication. Even so, the severity of handicap in patients emerging from consciousness disorders must also be anticipated as best we can, and it is important to integrate the experiences of the patient's relatives, healthcare workers, and wherever possible the patient too [92].

Adverse effects of DBS are difficult to anticipate in this context, as most studies, particularly the most recent, have used stimulation parameters that preclude severe adverse effects, and the clinical improvements achieved remain relatively modest. Nevertheless, looking at the wide experience reported in DBS for neurodegenerative disorders, it would be surprising if DBS did not come up with adverse effects at some point in time.

Resolving technical challenges for surgery, such as directly identifying anatomo-functional targets on brain images, should be an important step forward to aid in placing electrodes in stereotactic conditions and make it possible to control electrode position and thus analyse clinical effects according to the real electrode contact position instead of intended targeting.

Beyond technical and pathophysiological considerations, we also need clinical scales of conscious behaviour assessment that are more reliable, less ambiguous, and easily feasible at patient bedside. Integrating clinical data with functional data, such as fMRI, PET-scan and neurophysiology, would also likely prove useful both before and after DBS electrode implantation, but unfortunately the intra-cerebral electrodes developed to date preclude postoperative fMRI studies.

\section{Disclosure of interest}

The authors declare that they have no conflicts of interest concerning this article.

\section{References}

[1] M.I. Hariz, P. Blomstedt, L. Zrinzo Deep brain stimulation between 1947 and 1987: the untold story Neurosurg Focus, 29 (2010), p. E1, 10.3171/2010.4.FOCUS10106

[2] P. Coubes, L. Cif, H. El Fertit, et al. Electrical stimulation of the globus pallidus internus in patients with primary generalized dystonia: long-term results J Neurosurg, 101 (2004), pp. 189-194, 10.3171/jns.2004.101.2.0189

[3] A. Castrioto, A.M. Lozano, Y.Y. Poon, A.E. Lang, M. Fallis, E. Moro Ten-year outcome of subthalamic stimulation in Parkinson disease: a blinded evaluation Arch Neurol, 68 (12) (2011), pp. 15501556, 10.1001/archneurol.2011.182 
[4] K. Zhang, S. Bhatia, M.Y. Oh, D. Cohen, C. Angle, D. Whiting Long-term results of thalamic deep brain stimulation for essential tremor J Neurosurg, 112 (2010), pp. 1271-1276, 10.3171/2009.10.JNS09371

[5] A.L. Benabid, N. Torres New targets for DBS Parkinsonism Relat Disord, 18 (Suppl. 1) (2012), pp. S21-S23, 10.1016/S1353-8020(11)70009-8

[6] A.L. Benabid, T. Costecalde, N. Torres, et al. Chapter 5 - Deep brain stimulation: BCI at large, where are we going to? M.G. Jens Schouenborg, N.D. Jens Schouenborg (Eds.), Progress in Brain Research., 194, Elsevier (2011), pp. 71-82

[7] N. Lipsman, D.B. Woodside, P. Giacobbe, et al. Subcallosal cingulate deep brain stimulation for treatment-refractory anorexia nervosa: a phase 1 pilot trial Lancet, 381 (2013), pp. 1361-1370, $10.1016 / \mathrm{S} 0140-6736(12) 62188-6$

[8] J.T. Giacino, S. Ashwal, N. Childs, et al. The minimally conscious state: definition and diagnostic criteria Neurology, 58 (2002), pp. 349-353

[9] S. Laureys, F. Perrin, C. Schnakers, M. Boly, S. Majerus Residual cognitive function in comatose, vegetative and minimally conscious states Curr Opin Neurol, 18 (2005), pp. 726-733

[10] S. Laureys, G.G. Celesia, F. Cohadon, et al. Unresponsive wakefulness syndrome: a new name for the vegetative state or apallic syndrome BMC Med, 8 (2010), p. 68, 10.1186/1741-7015-8-68

[11] M.A. Bruno, A. Vanhaudenhuyse, A. Thibaut, G. Moonen, S. Laureys From unresponsive wakefulness to minimally conscious PLUS and functional locked-in syndromes: recent advances in our understanding of disorders of consciousness J Neurol, 258 (2011), pp. 1373-1384, 10.1007/s00415-0116114-x

[12] S. Laureys, N.D. Schiff Coma and consciousness: paradigms (re)framed by neuroimaging Neuroimage, 61 (2012), pp. 478-491, 10.1016/j.neuroimage.2011.12.041

[13] A. Demertzi, A. Soddu, S. Laureys Consciousness supporting networks Curr Opin Neurobiol, 23 (2013), pp. 239-244, 10.1016/j.conb.2012.12.003

[14] T. McLardy, F. Ervin, V. Mark, W. Scoville, W. Sweet Attempted inset-electrodes-arousal from traumatic coma: neuropathological findings Trans Am Neurol Assoc, 93 (1968), pp. 25-30

[15] R. Hassler, G.D. Ore, G. Dieckmann, A. Bricolo, G. Dolce Behavioural and EEG arousal induced by stimulation of unspecific projection systems in a patient with post-traumatic apallic syndrome Electroencephalogr Clin Neurophysiol, 27 (1969), pp. 306-310

[16] V. Sturm, A. Kühner, H.P. Schmitt, H. Assmus, G. Stock Chronic electrical stimulation of the thalamic unspecific activating system in a patient with coma due to midbrain and upper brain stem infarction Acta Neurochir (Wien), 47 (1979), pp. 235-244

[17] F. Cohadon, E. Richer, A. Rougier, P. Deliac, H. Loiseau Deep brain stimulations in cases of prolonged post-traumatic unconsciousness J. Gybels, E.R. Hitchcock, C. Ostertag, G.F. Rossi, J. Siegfried, G. Szikla (Eds.), Advances in Stereotactic and Functional Neurosurgery 6, 33, Springer-Verlag, Vienna (1984), pp. 535-537 
[18] F. Cohadon, E. Richer, A. Rougier, P. Deliac, H. Loiseau Deep brain stimulation in cases of prolonged post-traumatic unconsciousness Y. Lazorthes, A.R.M. Upton (Eds.), Neurostimulation: an overview, Futura Publishing Company, Mt. Kisco, New York (1985), pp. 247-250

[19] F. Cohadon, E. Richer [Deep cerebral stimulation in patients with post-traumatic vegetative state, 25 cases] Neurochirurgie, 39 (1993), pp. 281-292

[20] T. Tsubokawa, T. Yamamoto, Y. Katayama, T. Hirayama, S. Maejima, T. Moriya Deep brain stimulation in a persistent vegetative state: follow-up results and criteria for selection of candidates Brain Inj, 4 (1990), pp. 315-327

[21] T. Yamamoto, Y. Katayama, K. Kobayashi, H. Oshima, C. Fukaya, T. Tsubokawa Deep brain stimulation for the treatment of vegetative state Eur J Neurosci, 32 (2010), pp. 1145-1151, $10.1111 / \mathrm{j} .1460-9568.2010 .07412 . x$

[22] N.D. Schiff, J.T. Giacino, K. Kalmar, et al. Behavioural improvements with thalamic stimulation after severe traumatic brain injury Nature, 448 (2007), pp. 600-603, 10.1038/nature06041

[23] G. Moruzzi, H.W. Magoun Brain stem reticular formation and activation of the EEG Electroencephalog Clin Neurophysiol, 1 (1949), pp. 455-473, 10.1016/0013-4694(49)90219-9

[24] M. Steriade, L.L. Glenn Neocortical and caudate projections of intralaminar thalamic neurons and their synaptic excitation from midbrain reticular core J Neurophysiol, 48 (2) (1982), pp. 352-371

[25] A. Zeman Consciousness Brain, 124 (2001), pp. 1263-1289

[26] G. Dieckmann Cortical synchronized and desynchronized responses evoked by stimulation of the putamen and pallidum in cats J Neurol Sci, 7 (1968), pp. 385-391, 10.1016/0022-510X(68)90157-3

[27] F. Plum, J. Posner The diagnosis of stupor and coma (3rd ed.), F.A. Davis Company, Philadelphia (1980)

[28] P. Deliac, E. Richer, J. Berthomieu, J. Paty, F. Cohadon, C. Bensch [Electrophysiological development under thalamic stimulation of post-traumatic persistent vegetative states. A propos of 25 cases] Neurochirurgie, 39 (5) (1993), pp. 293-303

[29] T. Yamamoto, Y. Katayama, H. Oshima, C. Fukaya, T. Kawamata, T. Tsubokawa Deep brain stimulation therapy for a persistent vegetative state Acta Neurochir Suppl, 79 (2002), pp. 79-82

[30] T. Yamamoto, Y. Katayama, K. Kobayashi, M. Kasai, H. Oshima, C. Fukaya DBS therapy for a persistent vegetative state: ten years follow-up results Acta Neurochir Suppl, 87 (2003), pp. 15-18

[31] T. Yamamoto, K. Kobayashi, M. Kasai, H. Oshima, C. Fukaya, Y. Katayama DBS therapy for the vegetative state and minimally conscious state Acta Neurochir Suppl, 93 (2005), pp. 101-104

[32] N.D. Schiff, D. Rodriguez-Moreno, A. Kamal, et al. MRI reveals large-scale network activation in minimally conscious patients Neurology, 64 (2005), pp. 514-523, 10.1212/01.WNL.0000150883.10285.44

[33] JFK Coma Recovery Scale - Revised. Available at: http://www.tbims.org/combi/crs/index.html. 
[34] L. Manchikanti Evidence-based medicine, systematic reviews, and guidelines in interventional pain management, part I: introduction and general considerations Pain Physician, 11 (2008), pp. 161-186

[35] R. Nieuwenhuys, J. Voogd, C. Huijzen The human central nervous system: a synopsis and atlas Springer-Verlag, Berlin (1979)

[36] A. Morel, M. Magnin, D. Jeanmonod Multiarchitectonic and stereotactic atlas of the human thalamus J Comp Neurol, 387 (1997), pp. 588-630

[37] G. Schaltenbrand, P. Bailey Introduction to stereotaxis with an atlas of the human brain Georg Thieme Verlag, Stuttgart (1959)

[38] A. Parent Carpenter's human neuroanatomy Williams \& Wilkins, Baltimore (1996)

[39] T.E.J. Behrens, H. Johansen-Berg, M.W. Woolrich, et al. Non-invasive mapping of connections between human thalamus and cortex using diffusion imaging Nat Neurosci, 6 (7) (2003), pp. 750-757, $10.1038 / \mathrm{nn} 1075$

[40] A.F. Sadikot, V.V. Rymar The primate centromedian parafascicular complex: anatomical organization with a note on neuromodulation Brain Res Bull, 78 (2009), pp. 122-130, 10.1016/j.brainresbull.2008.09.016

[41] N.D. Schiff Central thalamic contributions to arousal regulation and neurological disorders of consciousness Ann N Y Acad Sci, 1129 (2008), pp. 105-118, 10.1196/annals.1417.029

[42] D. Pinault The thalamic reticular nucleus: structure, function and concept Brain Res Brain Res Rev, 46 (2004), pp. 1-31, 10.1016/j.brainresrev.2004.04.008

[43] K. McAlonan, J. Cavanaugh, R.H. Wurtz Guarding the gateway to cortex with attention in visual thalamus Nature, 456 (2008), pp. 391-394, 10.1038/nature07382

[44] B.K. Min A thalamic reticular networking model of consciousness Theor Biol Med Model, 7 (2010), p. $10,10.1186 / 1742-4682-7-10$

[45] E. Alexander Jr., J. Kushner, E.G. Six Brainstem hemorrhages and increased intracranial pressure: from Duret to computed tomography Surg Neurol, 17 (1982), pp. 107-110

[46] M. Bočková, J. Chládek, P. Jurák, J. Halámek, M. Baláž, I. Rektor Involvement of the subthalamic nucleus and globus pallidus internus in attention J Neural Transm, 118 (2011), pp. 1235-1245, 10.1007/s00702-010-0575-4

[47] M. Lazarus, Z.L. Huang, J. Lu, Y. Urade, J.F. Chen How do the basal ganglia regulate sleep-wake behavior? Trends Neurosci, 35 (2012), pp. 723-732, 10.1016/j.tins.2012.07.001

[48] E.G. Jones Viewpoint: the core and matrix of thalamic organization Neuroscience, 85 (1998), pp. $331-345$

[49] E.G. Jones The thalamic matrix and thalamocortical synchrony Trends Neurosci, 24 (2001), pp. 595601 
[50] M.C. Münkle, H.J. Waldvogel, R.L. Faull The distribution of calbindin, calretinin and parvalbumin immunoreactivity in the human thalamus J Chem Neuroanat, 19 (2000), pp. 155-173

[51] R.R. Llinas, E. Leznik, F.J. Urbano Temporal binding via cortical coincidence detection of specific and non-specific thalamocortical inputs: a voltage-dependent dye-imaging study in mouse brain slices Proc Natl Acad Sci U S A, 99 (2002), pp. 449-454, 10.1073/pnas.012604899

[52] E.E. Benarroch The midline and intralaminar thalamic nuclei: anatomic and functional specificity and implications in neurologic disease Neurology, 71 (2008), pp. 944-949, 10.1212/01.wnl.0000326066.57313.13

[53] F. Lombardi, M. Taricco, A. De Tanti, E. Telaro, A. Liberati Sensory stimulation of brain-injured individuals in coma or vegetative state: results of a Cochrane systematic review Clin Rehabil, 16 (2002), pp. $464-472$

[54] T. Kanno, I. Morita, S. Yamaguchi, et al. Dorsal column stimulation in persistent vegetative state Neuromodulation, 12 (2009), pp. 33-38, 10.1111/j.1525-1403.2009.00185.x

[55] T. Yamamoto, Y. Katayama, T. Obuchi, K. Kobayashi, H. Oshima, C. Fukaya Spinal cord stimulation for treatment of patients in the minimally conscious state Neurol Med Chir (Tokyo), 52 (2012), pp. 475-481

[56] M. Aalbers, J. Vles, S. Klinkenberg, G. Hoogland, M. Majoie, K. Rijkers Animal models for vagus nerve stimulation in epilepsy Exp Neurol, 230 (2011), pp. 167-175, 10.1016/j.expneurol.2011.04.014

[57] M.S. George, H.A. Sackeim, A.J. Rush, et al. Vagus nerve stimulation: a new tool for brain research and therapy Biol Psychiatry, 47 (2000), pp. 287-295

[58] J.B. Cooper, J.A. Jane, W.M. Alves, E.B. Cooper Right median nerve electrical stimulation to hasten awakening from coma Brain Inj, 13 (1999), pp. 261-267

[59] J.T. Liu, J.K. Lee, Y.S. Tyan, C.Y. Liu, T.B. Lin Change in cerebral perfusion of patients with coma after treatment with right median nerve stimulation and hyperbaric oxygen Neuromodulation, 11 (2008), pp. 296-301, 10.1111/j.1525-1403.2008.00179.x

[60] F. Piccione, M. Cavinato, P. Manganotti, et al. Behavioral and neurophysiological effects of repetitive transcranial magnetic stimulation on the minimally conscious state: a case study Neurorehabil Neural Repair, 25 (2011), pp. 98-102, 10.1177/1545968310369802

[61] S. Dehaene, L. Naccache Towards a cognitive neuroscience of consciousness: basic evidence and a workspace framework Cognition, 79 (2001), pp. 1-37

[62] M. Corbetta, G.L. Shulman Control of goal-directed and stimulus-driven attention in the brain Nat Rev Neurosci, 3 (2002), pp. 201-215, 10.1038/nrn755

[63] S. Laureys The neural correlate of (un)awareness: lessons from the vegetative state Trends Cogn Sci (Regul Ed), 9 (2005), pp. 556-559, 10.1016/j.tics.2005.10.010

[64] S. Canavero, B. Massa-Micon, F. Cauda, E. Montanaro Bifocal extradural cortical stimulationinduced recovery of consciousness in the permanent post-traumatic vegetative stateJ Neurol, 256 (2009), pp. 834-836, 10.1007/s00415-009-5019-4 
[65] T.L.B. Pape, J. Rosenow, G. Lewis, et al. Repetitive transcranial magnetic stimulation-associated neurobehavioral gains during coma recovery Brain Stimul, 2 (2009), pp. 22-35, 10.1016/j.brs.2008.09.004

[66] T.L.B. Pape, C. Tang, A. Guernon, et al. Predictive value of the Disorders of Consciousness Scale (DOCS) PM R, 1 (2009), pp. 152-161, 10.1016/j.pmrj.2008.11.002

[67] C. Di Rocco, G. Maira, M. Meglio, G.F. Rossi L-DOPA treatment of comatose states due to cerebral lesions. Preliminary findings J Neurosurg Sci, 18 (1974), pp. 169-176

[68] W. Matsuda, Y. Komatsu, K. Yanaka, A. Matsumura Levodopa treatment for patients in persistent vegetative or minimally conscious states Neuropsychol Rehabil, 15 (2005), pp. 414-427, $10.1080 / 09602010443000588$

[69] E. Richer, L. Tell [Indications, efficacy and tolerance of drug therapy in view of improving recovery of consciousness following a traumatic brain injury] Ann Readapt Med Phys, 46 (2003), pp. 177-183

[70] E.A. Fridman, B.Z. Krimchansky, M. Bonetto, et al. Continuous subcutaneous apomorphine for severe disorders of consciousness after traumatic brain injury Brain Inj, 24 (2010), pp. 636-641, $10.3109 / 02699051003610433$

[71] R.P. Clauss Neurotransmitters in coma, vegetative and minimally conscious states, pharmacological interventions Med Hypotheses, 75 (2010), pp. 287-290, 10.1016/j.mehy.2010.03.005

[72] J.T. Giacino, J. Whyte, E. Bagiella, et al. Placebo-controlled trial of amantadine for severe traumatic brain injury N Engl J Med, 366 (2012), pp. 819-826, 10.1056/NEJMoa1102609

[73] J. Whyte, R. Myers Incidence of clinically significant responses to zolpidem among patients with disorders of consciousness: a preliminary placebo-controlled trial Am J Phys Med Rehabil, 88 (2009), pp. 410-418, 10.1097/PHM.0b013e3181a0e3a0

[74] F. Pistoia, E. Mura, S. Govoni, M. Fini, M. Sarà Awakenings and awareness recovery in disorders of consciousness: is there a role for drugs? CNS Drugs, 24 (2010), pp. 625-638, 10.2165/11535940000000000-00000

[75] T. Taira Intrathecal administration of GABA agonists in the vegetative state Prog Brain Res, 177 (2009), pp. 317-328, 10.1016/S0079-6123(09)17721-X

[76] G.M. Earhart, M. Hong, S.D. Tabbal, J.S. Perlmutter Effects of thalamic stimulation frequency on intention and postural tremor Exp Neurol, 208 (2007), pp. 257-263, 10.1016/j.expneurol.2007.08.014

[77] E. Moro, P. Piboolnurak, T. Arenovich, S.W. Hung, Y.Y. Poon, A.M. Lozano Pallidal stimulation in cervical dystonia: clinical implications of acute changes in stimulation parameters Eur $\mathrm{J}$ Neurol, 16 (2009), pp. 506-512, 10.1111/j.1468-1331.2008.02520.x

[78] A.L. Benabid, P. Pollak, A. Louveau, S. Henry, J. de Rougemont Combined (thalamotomy and stimulation) stereotactic surgery of the VIM thalamic nucleus for bilateral Parkinson disease Appl Neurophysiol, 50 (1987), pp. 344-346

[79] T. Xie, U.J. Kang, P. Warnke Effect of stimulation frequency on immediate freezing of gait in newly activated STN DBS in Parkinson's disease J Neurol Neurosurg Psychiatr, 83 (2012), pp. 1015-1017, 10.1136/jnnp-2011-302091 
[80] G.F. Molnar, A. Sailer, C.A. Gunraj, et al. Changes in cortical excitability with thalamic deep brain stimulation Neurology, 64 (2005), pp. 1913-1919, 10.1212/01.WNL.0000163985.89444.DD

[81] S. Tisch, J.C. Rothwell, K.P. Bhatia, et al. Pallidal stimulation modifies after-effects of paired associative stimulation on motor cortex excitability in primary generalised dystonia Exp Neurol, 206 (2007), pp. 80-85, 10.1016/j.expneurol.2007.03.027

[82] N. Yamawaki, P.J. Magill, G.L. Woodhall, S.D. Hall, I.M. Stanford Frequency selectivity and dopamine-dependence of plasticity at glutamatergic synapses in the subthalamic nucleus Neuroscience, 203 (2012), pp. 1-11, 10.1016/j.neuroscience.2011.12.027

[83] K. Kumar, C. Toth, R.K. Nath Deep brain stimulation for intractable pain: a 15-year experience Neurosurgery, 40 (1997), pp. 736-746

[84] C.M. Feng, S. Narayana, J.L. Lancaster, et al. CBF changes during brain activation: fMRI vs. PET Neuroimage, 22 (2004), pp. 443-446, 10.1016/j.neuroimage.2004.01.017

[85] A. Estraneo, P. Moretta, V. Loreto, B. Lanzillo, L. Santoro, L. Trojano Late recovery after traumatic, anoxic, or hemorrhagic long-lasting vegetative state Neurology, 75 (2010), pp. 239-245, 10.1212/WNL.0b013e3181e8e8cc

[86] J. Luauté, D. Maucort-Boulch, L. Tell, et al. Long-term outcomes of chronic minimally conscious and vegetative states Neurology, 75 (2010), pp. 246-252, 10.1212/WNL.0b013e3181e8e8df

[87] H.U. Voss, A.M. Uluç, J.P. Dyke, et al. Possible axonal regrowth in late recovery from the minimally conscious state J Clin Invest, 116 (2006), pp. 2005-2011, 10.1172/JCI27021

[88] F. Faugeras, B. Rohaut, N. Weiss, et al. Probing consciousness with event-related potentials in the vegetative state Neurology, 77 (2011), pp. 264-268, 10.1212/WNL.0b013e3182217ee8

[89] J. Luauté, F. Cotton, J.J. Lemaire, et al. Let live or let die after traumatic coma. Scrutinizing somatosensory evoked potentials Neurol Clin Pract, 2 (2012), pp. 24-32, 10.1212/CPJ.0b013e318246cab

[90] L. Naci, M.M. Monti, D. Cruse, et al. Brain-computer interfaces for communication with nonresponsive patients Ann Neurol, 72 (2012), pp. 312-323, 10.1002/ana.23656

[91] D. Galanaud, V. Perlbarg, R. Gupta, et al. Assessment of white matter injury and outcome in severe brain trauma: a prospective multicenter cohort Anesthesiology, 117 (2012), pp. 1300-1310, 10.1097/ALN.0b013e3182755558

[92] D. Lulé, C. Zickler, S. Häcker, et al. Life can be worth living in locked-in syndrome Prog Brain Res, 177 (2009), pp. 339-351, 10.1016/S0079-6123(09)17723-3

[93] J. Lemaire, L. Sakka, L. Ouchchane, F. Caire, J. Gabrillargues, J. Bonny Anatomy of the human thalamus based on spontaneous contrast and microscopic voxels in high-field magnetic resonance imaging Neurosurgery, 66 (3 Suppl. Operative) (2010), pp. 161-172, 10.1227/01.NEU.0000365617.41061.A3

French NeuroAnesthesia and Intensive Care society Meeting, Paris, November 2013, 21st and 22nd: "The acutely brain-injured patient: consciousness and neuroethic". 